\title{
Custom and Citizenship in the Philippine Uplands
}

\author{
Oona Paredes
}

Ethnic minorities tend to have a contentious relationship with state institutions and the national majorities the state in effect represents. 'Indigenous peoples' - the global political term for 'tribal' peoples and other comparable sub-regional minorities (hereafter IP's) - are often specifically excluded or otherwise marginalized in their home countries. ${ }^{1}$ In Southeast Asia and elsewhere, 'tribal' IP's are typically regarded as the weakest link in the nation's socio-economic advancement, especially where their cultural distinctiveness is explained in nationalist discourse as primitivity or backwardness (Brosius 2003). Even when their legal citizenship is acknowledged, as ethnic minorities they are never sufficiently 'citizenly' in the eyes of the national majorities that control the state. ${ }^{2}$ As such, it is common to find the concerns of IP's ignored routinely, and their citizenship delegitimized, ultimately driving them to contest the state's cultural hegemony in the context of what anthropologist Peter Brosius (2003:121) has called 'a politics of desperation'. It is a condition of political and cultural exclusion that structures significantly the way IP's experience 'democracy', and how they understand, as well as practice, their own citizenship.

The Philippines is no exception, where the exclusion of its IP's is implicit in its current historiography, and reiterated in the structure of its government. The notion of the 'Filipino' as citizen monosubject is explicit in nationalist discourse, where the majority is Hispanized and Catholicized, whilst tribal minorities are stereotyped as living fossils of pre-colonial culture, and on some level regarded as racially inferior and mentally deficient. ${ }^{3}$ Reinforcing their exclusion from mainstream society, IP's are administered separately - a setup that, while originally intended to protect this vulnerable population, has

1 'Indigenous peoples' is used here as a political rather than cultural designation. Despite the presence of IP's throughout Southeast Asia, technically speaking most of its people, even the ethnic majorities, are indigenous to the region. While there are many local terms for a country's indigenous 'tribal' minorities, the Philippine government uses the English term 'indigenous peoples' to refer to this population officially. I follow this usage here, shortened to 'IP', which is now the common practice in the Philippines, even among the IP's themselves.

2 Here I draw on the concept of 'graduated citizenship', as discussed in McCargo (2011).

3 I have addressed this topic extensively in previous work. See Paredes (2000), and Paredes (2013), especially pages $7-9$ for the latter. 
become a hurdle to the exercise of their citizenship rights. IP's may be recognized formally as Filipino citizens today, but in the majority of the population, informal notions of citizenship continue to privilege a homogenized, Catholic 'national' monoculture to which IP's and other minorities are, at best, quaint addenda.

If the fundamental paradox of the region's democratization may be the survival of unequal patron - client relationships, the situation of IP's goes one step further. In the case of Philippine IP's, their attempted 'empowerment' through participatory democracy seems to further entrench their political exclusion and increase their risk of exploitation, as their continued administrative separation complicates governance and propels IP's into unequal, clientelistic relationships with often predatory outsiders in order to accomplish even the most basic bureaucratic tasks. At the same time, in their attempts to exercise their citizenship, IP's face overwhelming pressure to conform to mainstream Filipino culture at the expense of the very cultural traditions they are fighting to preserve. In this chapter I explore the longstanding exclusion of IP's in the region, and how it manifests itself in terms of citizenship and democratization, drawing on my ongoing research with the Higaunon of Mindanao, in the southern Philippines. ${ }^{4}$ I focus specifically on the impact of these exclusions on the experience and exercise of citizenship by Higaunons, and the long-term implications of the widening procedural and cultural gaps between their traditional political systems and the decentralized bureaucracies of the state - gaps that have developed alongside increased Higaunon political participation in the Philippine democracy.

The Higaunon case outlines some of the dilemmas of citizenship for IP's, not only in the Philippines but throughout postcolonial Southeast Asia. Given that the modern nation-states of ASEAN were built on the same colonial foundations, the status of today's IP's can be traced largely to their peripheral status

4 The material in this chapter is based on the sum of my research involving Higaunons in northern Mindanao, beginning with my MA field research in 1995 and correspondence and field visits since then, as well as regular communication with the national government agencies that administer IP affairs (OSCC and now NCIP [National Commission on Indigenous Peoples]), and workers from NGOs that have had dealings with Higaunons. The more recent information presented here is drawn from my preliminary findings in an ongoing (since 2012) field research project focused specifically on the impact of government bureaucracy on the exercise of indigenous political authority of datu and bae leaders, and another project running concurrently on oral history. The former is supported by a research grant from the National University of Singapore, and the latter by the Firebird Foundation for Anthropological Research. Due to the sensitive nature of this topic, as well as the unpredictability of local politics, I must keep my indigenous informants and other sources anonymous. 
relative to the colonial-era metropoles where conceptions of postcolonial nationhood and citizenship were originally developed and negotiated by new elites and ethnic majorities. Following Duncan McCargo (2011), citizenship has not only formal aspects (pertaining to government-recognized citizenship) but significant informal aspects (pertaining to culture) as well. With respect to its informal or 'vernacular' aspects, Renato Rosaldo (2003:1-2) points to the power of national metropoles to marginalize the ethnic minorities at their peripheries, in effect 'excluding them from full national citizenship' through the politics of difference. Coining the term 'cultural citizenship' to highlight how minorities negotiate the informal aspects of 'belonging', Rosaldo explains that citizenship is a process that takes place 'within a social field anchored in the cultural distinction between the metropolis and its hinterlands' where 'issues of citizenship become cultural' (Rosaldo 2003:3-4). Amongst the IP's of Southeast Asia in particular, ' $[t]$ he cultural question animating such dynamics focuses on how subordinated or marginalized groups define and experience their humiliation and their striving for well-being, respect, and dignity.' In the Higaunon case, we can see the active, multifaceted pursuit of fuller citizenship by individuals and communities typical of IP's. We also see how, in their desire to participate in Philippine democracy, Higaunons are transforming radically the ancestral traditions around which their ethnic identity had previously revolved.

\section{Cultural Citizenship in Mindanao}

As in most of Southeast Asia, local political history in Mindanao revolves around an ethnicized upland-lowland axis, with the island's indigenous peoples largely displaced to the interior uplands by the migration of Filipino settlers from other, over-populated regions of the Philippines - a demographic upheaval that has transformed Mindanao rapidly and radically. The indigenous peoples of Mindanao are divided into two categories: the primarily Muslim ethnic groups, collectively called the Moros, and the non-Muslim ethnic groups, collectively called the Lumad. The Lumad, in turn, are one of the two largest sub-categories of Philippine IP's (the other being the Cordillerans of northern Luzon). Among the eighteen or so Lumad ethnic groups, the Higaunon are today one of the largest, ${ }^{5}$ with multiple descent groups distributed across five provinces in northern Mindanao: Lanao del Norte, Misamis Oriental, Bukidnon, Agusan del Norte and Agusan del Sur. Their modern territory includes the

5 Estimated Higaunon population total is upwards of 250,000. 
mountain ranges that divide these provinces, and historically their economic life has revolved around forest swiddening supplemented by hunting and the collection of forest products like rattan and tree resins - and in recent decades, the individual collection of timber through 'carabao logging' 6 - for buyers in the lowlands.

Mindanao was dominated historically by a succession of Moro sultanates, to whom Lumad peoples paid tribute, but the political environment slowly changed as the region became incorporated (albeit imperfectly) into Spanish and later American colonial regimes. By the time of Philippine independence in 1946, the country was dominated by lowland-based ethnic majorities with the heavily Christianized and Hispanized cultures we recognize today as normatively 'Filipino'. Soon after World War II, these 'Christian' Filipinos colonized the southern Philippines in search of arable land. These settlers - whom the Higaunons call dumagat or 'coastal people'- now constitute an overwhelming majority, at more than seventy percent of Mindanao's population. Moro groups, down to approximately twenty percent despite consistently high birth rates, have since become the island's primary minorities. Meanwhile, the Lumad groups have diminished even more in status, being the smallest demographic minority overall (at ten percent or less of the island's population), as well as second-order minorities - basically, minoritized by another minority group - within the Moro territories. ${ }^{7}$ In the Moro-dominated areas of western Mindanao, the government's pro-settler policies (including support for armed militias) contributed directly to the outbreak of violence in the 1970s, and a sustained armed rebellion by Moros that is now manifested in the push for Moro autonomy. As second-order minorities in these Moro territories, the Lumads have been caught in the crossfire of competing factions since the beginning of the Bangsmoro rebellion in the 196os. Elsewhere in Mindanao, the 'Christian' Filipino settlers have also displaced the Lumads radically, though the Lumad response has been disorganized and largely futile in the face of land-grabbing by settlers and corporate industries, likely due to the small scale and scattered

6 This involves either the use of water buffalo or carabao to drag logs to the buyer pickup areas. However, Higaunons rarely have their own carabao and often turn to moving the heavy logs themselves by either carrying them over their shoulders or tying a rope around their waists to drag the log along. Children are also known to engage in this activity, which is called drageng in Higaunon (from the English word 'dragging').

7 The available statistics remain imprecise due to inadequate coverage in Mindanao and the fact that ethnicity is not officially reported in the national census (Montiel et al., 2012; Gaspar 2013). See Paredes (2015) for a discussion of Lumads as second-order minorities. See Barter (2015) for a broader discussion of second-order minorities in Asia. 
distribution of these communities. ${ }^{8}$ While in most Lumad communities there has been some intermarriage with the dumagat settlers, their overall political relationship remains highly contentious at the municipal and provincial level, particularly with regard to land.

The Lumads themselves recognize easily the relative privilege inherent to being born a dumagat: despite the fact that many live at or below the poverty level, membership in mainstream Filipino groups provides linguistic, cultural and religious advantages unavailable to Lumads other Philippine IP's. For one, the Philippine government bureaucracy is dominated by dumagats, and historically what the state considers 'national' interests - particularly in regard to the 'development' of Mindanao - have been synonymous with dumagat interests. Their resettlement to Mindanao, for example, was encouraged originally by loans and subsidies, infrastructure development catering to migrants' needs, and other structural support from the national government. In contrast, the IP's have faced a persistent lack of recognition from the same bureaucracies, due to a combination of racial prejudice and jurisdictional confusion, in that the national government has always administered the affairs of the indigenous minorities separately. ${ }^{9}$

Since 1997, the National Commission on Indigenous Peoples (NCIP) has been tasked with the special needs of IP's, and while there are NCIP satellite offices throughout the country, the NCIP is a national bureaucracy that is separate from the decentralized system of local governance, discussed in the next section. However, this national-level administrative apparatus for IP's has never been comprehensive, leaving out practically all the basic necessities of a normal citizen, such as healthcare, higher education, finance, taxation, entrepreneurship, transportation, social security, voting and identity papers, among others things. Instead, these basic necessities must be accessed by IP's not through the NCIP but at different levels of the local government system. Such inadequacies have driven some IP's to break out of the NCIP's bureaucratic constraints and fight for inclusion in mainstream Filipino society. But as IP's have more actively embraced and demanded their citizenship rights, they

8 See Paredes (1997). The presence of logging and mining operations in Lumad areas has long been a political and environmental problem. This is also the case for IP areas not only in Southeast Asia but also the rest of the world.

9 This administrative separation is a legacy of the American colonial period, during which the 'non-Christian tribes', including the Moros, were believed by the Americans to still be at different stages of cultural and intellectual development than mainstream Filipinos, and therefore requiring other interventions and special protection from the majority. See the article by R.J. May (2009). This history is also outlined on the website of the present-day National Commission on Indigenous Peoples at http://ncipro67.com.ph/ncip/history/. 
have had to navigate both the government bureaucracy and Filipino/dumagat culture more or less on their own. At the same time, racial prejudice against IP's remains a major barrier in their interactions with the dumagats who run these bureaucracies at all levels.

\section{Decentralization and the Higaunon Experience}

The general impact of government decentralization in the Philippines, through the establishment of the local government unit (LGU) system, has already been described by Emma Porio in Chapter 2 of this volume. With the goal of fostering greater democratization, the LGU system promotes the administrative autonomy of individual government units, from the regional and provincial levels down to the smallest government unit called a barangay. ${ }^{10}$ While this decentralized mode does foster highly localized forms of governance, as Porio's chapter shows, it ultimately reinforces economic inequalities and further entrenches the power of political elites in lowland cities and towns. The IP experience, though distinct, mirrors many of the transformations engendered by government decentralization in the lowlands. However, the IP experience is intensified politically by factors peculiar to IP communities, such as their administrative separation from 'normal' Filipinos and their liminality vis-à-vis mainstream Filipino culture and life, especially in the already peripheral Philippine south, and the resulting prejudice and discrimination they face from dumagats who regard them as inferiors. Whilst poor dumagats sometimes do have to engage in small-scale bribery to access government services, IP's suffer the greater disadvantage of not being taken seriously at all, either due to their perceived savagery and imbecility, or simply their inability to pay even small-scale bribes. However, honest and professional dumagats may also find it difficult to interface with many IP's due to linguistic issues, or the logistical barriers of dealing with remote upland communities.

Within the context of this administrative separation, however, the IP's have managed to make some legal advances, especially with regard to the recognition of their ancestral land rights. The Indigenous Peoples Rights Act of 1997 (or IPRA) modified the Spanish-era land laws that had prevented the private

10 The barangay is the smallest local government unit in the Philippines, corresponding roughly to a village or small town. Each city or municipality is made up of several barangays, depending on population size. Rural barangays generally cover larger areas, due to lower population density, whilst in a densely populated urban setting every other city block might be a separate barangay. 
titling of upland areas, where IP communities tend to be concentrated. ${ }^{11}$ Today, the national government mandates by law the integration of IP representatives within local government units in areas with a substantial IP population, but national and local government bureaucracies did not evolve in response to the needs of IP's, and any hard-won accommodations and legislative retrofits have come at a belated pace and may not be fully enforced. They have not in any way moderated the fundamental paradox of IP activism, as described by anthropologist Dorothy Hodgson (2011:6), in her study of Masaai identity politics in East Africa: 'that indigenous groups must demand recognition from the very nation-states that have historically treated them as second-class citizens (if citizens at all) by ignoring their rights, exploiting their resources, and disparaging their cultures and identities'. This is no easy feat, as they often must take extraordinary measures simply to ensure that their existing legal rights as citizens and IP's - are acknowledged by local authorities:

Demanding such recognition involves learning the relevant legal and bureaucratic categories and processes, lobbying at various levels and sites of government, appealing to popular media, seeking international support, and molding their images, identities, and agendas accordingly.

HODGSON 2011:6

In the case of Mindanao, the combination of government decentralization and racial prejudice has brought IP exclusion to the fore. Even in areas with large IP populations, local authorities tend to ignore or neglect the needs of IP's until the problem grows acute enough to have public consequences, such as when a confrontation - in which the local official faces the risk of embarrassment - is threatened or takes place. Dumagat officials, no matter how polite or courteous, are universally perceived by IP's to be indifferent to their concerns, and in some cases, disdainful and openly hostile. I have witnessed such bureaucratic malice occurring even when Higaunons come prepared with all the required identification and paperwork.

One particular case recently involved the types of incidents already familiar to researchers and advocates working with IP's. The central office of one state agency, in Manila, sent paperwork to its rural satellite office in northern

11 Full text of the IPRA law is available at http://www.gov.ph/1997/10/29/republic-act-no $-8371 /$. It is ironic that while IPRA is widely regarded as rather a belated consolation prize in light of all the IP lands that had been previously stolen, had national land laws allowed the private titling of upland areas earlier in the twentieth century, it is likely that all of these IP lands would today be owned by dumagats. 
Mindanao, certifying that a particular Higaunon community was to receive a set amount of government funding for a small economic development project. When the community inquired at the satellite office (run entirely by dumagat civil servants), the officials initially refused to respond, then later claimed to have 'lost' the hand-delivered paperwork. After a year of fruitless waiting, the community leaders, now restless, decided to propose an alternate project, only to be prevented from submitting it because the original project was apparently on the books as 'incomplete'. After the bureaucratic 'error' was cleared up with the Manila office, the Higaunons were forced to start all over again, with the satellite office requiring the Higaunons to attend new time-consuming 'orientation' meetings and pay costly new fees to produce and process the same paperwork. In order to prevent further delays, the community leaders simply did as they were told.

But it did not end there. After the final certification was once again sent down, this time from the agency's offices in both Manila and the provincial capital, community representatives went to collect their project funds, only to find that the satellite office had taken it upon themselves to assign the funds instead to a larger, neighbouring town that they felt would be better administrators for the project, possibly because the town's leader was a friend of the satellite office's manager. ${ }^{12}$ Despite their protestations and official paperwork, the community representatives were blithely ignored and told instead to take up the matter with their neighbours, with whom they have had a territorial feud ongoing since the late 199o's. Only when one of the Higaunon leaders raised the matter angrily and loudly at a public meeting attended by other agencies did the satellite officials begin to show any concern. However, it took further intervention from higher-ups in Manila and the provincial capital before the matter was fully resolved and the funds awarded to the Higaunon community that had originally proposed the project. ${ }^{13}$

Even quotidian Higaunon interactions with the dumagat-dominated state apparatus can prove to be stressful in the extreme thanks to a confluence of several factors: Higaunons' long-standing mistrust of dumagats, thanks to a

12 It was later revealed that the rival town was in no way involved in this fiasco, and that the officials at the satellite office had acted purely on their own initiative. In the immediate aftermath, the satellite office was placed under some administrative scrutiny by the provincial office, but today the same problematic dumagat officers still work there.

13 The community leaders in this case could not afford the long-distance calls, nor could they speak either English or Tagalog (Pilipino), the only bureaucratic languages of Manila. Due to bureaucratic malice, a process that should have taken less than a year lasted three years from proposal submission to actual disbursement of funds. 
century of uncontrolled land encroachment by settlers from Filipino majority ethnic groups; Higaunon ignorance of bureaucratic procedures, due in part to their illiteracy with respect to the official languages of Tagalog (Pilipino) and English; ${ }^{14}$ the already maddening opacity of Philippine government bureaucracy; and a compounding layer of dumagat prejudices against people they presume to be savages. It is the perfect storm of power-saturated ${ }^{15}$ interactions that both magnifies the Philippine state's existing vulnerabilities to graft and influence peddling - what Thomas McKenna (1998:130) refers to euphemistically as 'possibilities for self-enrichment' within the civil service - and increases the vulnerability of minority IP's to exploitation by the ethnic majorities. This vulnerability is also physical, in the literal sense that moving about in the foreign dumagat world is also extremely stressful to Higaunons, with the heat, noise, pollution, crowding and hurried pace of lowland towns often triggering headaches and other physical maladies that discourage them from persisting in such encounters.

As a result, clientelistic third party assistance is often sought by Higaunons even for such basic tasks as obtaining identification papers, filing tax forms, school registration, claiming and collecting government benefits, or opening a basic bank account. For more complex procedures such as raising funds for a community development project, registering a community organization with the Securities and Exchange Commission, or applying successfully for a government reforestation grant, direct intervention by a third party is often required in order to navigate the bureaucratic maze in a timely manner. This state of affairs has prompted Higaunons to not only accept but actively cultivate patron-client relationships with outsiders (such as government officials, merchants, NGO workers, local functionaries, politicians, wealthy individuals) who might be able to help them navigate the dumagat world and mobilize even the most basic resources to which they are already entitled either as citizens under Philippine law or as IP's under the IPRA.

14 The dominant dumagat language in northern Mindanao is Cebuano Visayan, which most Higaunons pick up either from their settler neighbours, from their classmates at school, or from their travels to the coastal markets such as those in Gingoog City. Whilst some school-age children have a limited fluency in Tagalog and English, very few adults possess more than a rudimentary vocabulary of Tagalog and English words. It is still possible to this day to find children growing up immersed in a Higaunon-only linguistic environment. Adults who do not travel regularly outside this environment may have some understanding of Cebuano Visayan, but not enough to speak it. Higaunons are thus doubly disadvantaged in terms of language.

I use 'power-saturated' here following Tania Murray Li's (2001) usage. 
In the process, Higaunons also come to embrace the material aspirations of lowland culture that they observe to be necessary for mainstream 'success' (such as formal schooling, urban life, full linguistic competence in dumagat languages, intermarriage with dumagats) in order to ease their movements in modern Philippine society. In other words, Higaunons fully understand that, in today's democracy, being more dumagat and less Lumad makes their lives easier, even if it means that they must face the very real dilemma of losing touch with their own culture and identity as they are pushed by well-meaning outsiders - and most often, by their own parents and elders - towards perfecting their assimilation into the dumagat world.

Amongst the Higaunon, I have observed on the one hand how, in the past two decades, state practices have genuinely transformed how they conceptualize their relationship to the national government, their received notions of 'citizenship' and 'democracy', and their growing identification as 'Filipino'. On the other hand, I have also observed how government decentralization has actually complicated and increased the bureaucratic contact required of IP leaders to take care of basic tasks of governance and provide social services and economic opportunities for their communities, as part of this quest for more involved citizenship. This in turn is transforming substantially their traditional notions and practices of governmentality as well as replicating, slowly but surely, the predatory and exclusionary aspects of Philippine national tra$p o^{16}$ politics. In other words, the pursuit of greater democratization, primarily through the principles of government decentralization and participatory development in both local government units and tribal affairs, is instead reproducing the predatory politics of the Philippine state, engendering gross power inequalities and political exclusions within small, kin-based, and libertarian Lumad communities. These new disparities, in turn, are causing troubling new entanglements that undermine indigenous governance.

\section{Political Leadership among Higaunon Lumads}

For outsiders and 'insiders' both, it is quite a challenge to get a grip on the internal politics of the Higaunon. This is because in public they emphasize consistently a high degree of social cohesion and solidarity, yet they are in fact highly individualistic, acting on a distinctly libertarian ethic. This is due in

16 Trapo is a Philippine term for a rag used for cleaning, widely used as a metaphor for corrupt or 'dirty' politicians. It is a play on words derived from the first syllables of the ironic phrase 'traditional politician'. 
part to demographic factors: their settlements are normally small-scale and almost entirely kin-based, with multiple closely-related family groups living in a specific territory delineated by their founding ancestors. They tend to be organized in loose, settlement-specific, and communalistic power structures headed by one or more men of high esteem, called datu, who descend from the founding families, the ininay daw inamay. ${ }^{17}$ Respected women from these families also take on very similar roles, with the title of bae, ${ }^{18}$ and in recent times many bae have risen to prominence in communities with less-than-effective male leadership.

According to Higaunon customary law (bungkatol ha bulawan), each settlement's founding families remain paramount in all things, with exclusive jurisdiction over land rights and political authority. Even though in-laws and others are often welcomed as new residents, only the ininay daw inamay may become datu or bae for a given territory. However, this still means that nearly all Higaunons have the right to put themselves forward as potential datu and bae in their home communities. In fact, each settlement, no matter how small, always has multiple datu and bae at the helm. Finally, though membership in the ininay daw inamay lineages is an ascribed status, leadership itself must be individually achieved. In other words, datuship involves heredity, but is not hereditary.

The ideal characteristics of a datu or a bae are: a definitive knowledge of customary law, mastery of the panud (oral history), commitment to the community, the ability to listen to others and treat everyone fairly, the ability to generate a public consensus, personal humility and a distaste for attentionseeking behaviour. They are not only community leaders and adjudicators of customary law, but are also the repositories of oral traditions as well as secret knowledge passed down from the ancestors. As such, the datu or bae is a living embodiment of Higaunon law, cultural tradition and historical memory. The datu or bae are thus the designated 'culture-bearers' of their communities, rather than holders of a particular political office. They are trained by their elders, under whose tutelage they ultimately matriculate in a sacred ritual called the dumalungdong, during which they receive their sacred datu name from the spirits. While in communication with outsiders, Higaunons freely refer to each other as datu or bae, but in fact only a handful of such individuals actually undergo training, and even less have ever been confirmed through the formal ritual. Within this small group, there are even fewer datu who would be regarded by Higaunons as truly embodying what, in their minds, is a 'real' datu.

17 This phrase refers literally to the original mothers and fathers (of the land).

18 The word is an honorific version of baye ('woman'). 
At the same time, however, Higaunons recognize that someone who adheres religiously to the bungkatol ha bulawan is the antithesis of the kind of leader present political circumstances require. And this is the point at which the question of indigenous leadership grows rather complicated.

To an outside observer without any prior experience of Higaunon customs, it would be difficult generally to guess who the true leaders of a community may be, because the 'traditional' datu and bae tends to be rather introverted, and the polar opposite of what dumagats would typically recognize and require in terms of political leadership. In public meetings and discussions I have observed, typically the most highly regarded datu in the room listens silently as everyone else voices their opinion, speaking up last and only to summarize and validate the points of view expressed and propose a way forward, at which point another round of opinion and debate often begins. However, it is also common to see a few men stand up and state their opinions vociferously, sometimes with such eloquence and force that an outsider would easily mistake them for the leader of the group. This is, after all, how dumagat politicians behave. But to Higaunons, such bluster is unimpressive because aggressive speech is seen not only as rude but also a mark of political immaturity. It is a subtle cultural difference that creates a fundamental problem of communication (and therefore governance) between Lumad peoples and state officials.

\section{The Rise of the Government datus}

The word datu is routinely translated into English as 'chieftain', inviting an automatic comparison and conflation with chieftains of the European, Native American or Polynesian model. However, the Higaunon datu does not appear to be like any of these types, nor even like the 'big-man' once described by Marshall Sahlins (1963) for Melanesia. For one, there are often quite a few datu in any given community, none with actual legal authority over the rest. Nor are individuals obliged to follow blindly the commands of a datu, in part because the status differences within Higaunon society do not extend to hierarchies of rank or class. While it remains poorly understood, it is fair to say that Higaunon customary law, as a political system, does not encourage the establishment of a centralized leadership, a permanent power hierarchy, or the significant accumulation of power by one individual. Instead, it demands consensus and engenders the cooperative dispersion of power. All the same, outsiders seem to expect, even require, a certain type of community leader, especially when it comes to dealing with the demands of participating in a modern democratic society. In response to the requirements of interacting with the state, local 
politics, the local market economy, non-governmental organizations and other outsiders, a new type of indigenous leader has evolved convergently in Lumad communities all across Mindanao.

The siptin, as s/he is called by the Higaunon as well as by other unrelated Lumad groups, is a relatively new type of tribal leader who stands as the political and legal representative for his or her community, the point-person for dealing with outsiders. S/he also gives the impression of an overall ruler who appears to make decisions on behalf of the whole community and likewise is generally held as responsible for enforcing community rules. In a nod to modern democratic ideals, a community's siptin is typically selected by consensus amongst the various datu and bae, and is open equally to women and men. It seems to be evolving into a universal type of tribal leadership role, such that the siptin appears to be generic across all the Lumad groups.

Siptin is, of course, derived from the English word 'chieftain', a word that has been internalized by Higaunons and other Lumads. There is no equivalent indigenous term in any Lumad language. It is fair to say that the role of siptin was not only created in order to conform to outsiders' expectations, it is a concept that has been imported wholesale from contacts with state bureaucracy. In the 1980 s, tribal communities wishing to interact in an official capacity with the national government (when Lumads fell under the auspices of the Office of Southern Cultural Communities) were required to provide first a list of 'tribal officers' for their 'tribal council', beginning with the 'chieftain' and going down the line to treasurer, secretary, sergeant-at-arms and other such officers normally found in the student councils of the Philippine elementary and secondary school system. In those days, such positions were filled almost randomly, with no correlation between title, function, or actual leadership status. Tribal councils were created ad hoc simply because the government required the paperwork, whether it was used to register a general complaint with the national government or to file an ancestral land claim.

Today, tribal councils are taken seriously, and have become an important organizing mechanism for communities with official ancestral land claims. In such cases, they form an important part of the actual leadership structures on the ground, as IP communities attempt to harmonize their political systems with that of the national government. But a designated 'chieftain' is still required, and so the siptin has become normalized within the indigenous political system. Amongst the Higaunon the office of siptin is not necessarily held by a ritually confirmed datu or bae, much less the highest ranking one amongst them. In fact, in two Higaunon communities I know well, neither siptin is ritually confirmed, but simply a member of the tribal council who was selected by the majority to do what none of the other datu or bae want to do, which is 
deal with outsiders. Often it is someone who is more at ease in dealing with dumagats, and more literate in the languages of government (Tagalog and English) than the rest.

Whilst the siptin may be referred to by the community as a datu or bae in the presence of outsiders, within the context of Higaunon customary law they are basically what other datu refer to as a datu ha gubilnu or 'government datu.' This is to differentiate the leadership of a siptin from that of a datu who follows the bungkatol ha bulawan, and who might therefore be called more properly a datu ha kultura or 'cultural datu'. Whilst undeniably a leader within the context of customary law, a well-respected cultural datu tends to be ineffective as a community interface in the power-saturated bureaucratic environment of the lowlands, due to the very nature of his vocation that prioritizes the preservation and proper exercise of cultural knowledge, and social protocols over the accumulation of individual power and influence.

The siptin is not the only 'government datu' to be found in the modern political system of the Higaunon. An equally important role may also be played by the sirman (from 'chairman'), who is the individual on record as the official holder of the community's Certificate of Ancestral Domain Claim or Title (CADC/CADT). In all the communities with which I am familiar, the role of sirman is never assigned to the same individual as the siptin, perhaps as a nod to the Higaunon ethos against the concentration of power. Like the siptin, however, the sirman is also selected for his or her ability to deal effectively with outsiders and represent the community, as needed, in dealings with the government. Also in the sirman's portfolio is responsibility for the actual management of the ancestral domain, as required for every CADC and CADT. This includes planning, applying for public and private funds, and organizing the community to implement any development strategies for the land, in fulfilment of IPRA requirements.

Though quite a recent invention of government bureaucrats who were concerned primarily with environmental protection, the concept of 'ancestral domain' in fact harmonizes easily (though not completely) with Higaunon ideas about both land tenure and governmentality. The participatory development aspects of the IPRA law also comport with the Higaunon ethos of listening and consensus-building. The Higaunons have therefore embraced the IPRA and taken advantage of it as much as possible. Among the Lumads, the Higaunon sub-groups have been the most involved in ancestral domain claims, with most communities filing official claims for recognition of their lands, or in some cases combining resources with neighbouring communities to file socalled 'unified' ancestral domain claims involving a much larger contiguous territory. 
While these domains are supposed to be autonomous and administered through the national government via the National Commission on Indigenous Peoples (NCIP), in practice all IP's, being Philippine citizens, must also articulate with the decentralized local government unit (LGU) system. This means that, in addition to customary law and the government's 'tribal council' system that has created siptins and sirmans, IP's are also incorporated into their corresponding LGUS, through which they exercise their right to vote, enter the public education system and connect with other aspects of the government bureaucracy that are not available through the NCIP. The LGU system also requires local residents to participate in their own governance, particularly at the basic level of the barangay, the smallest autonomous LGU. It is within this muddled articulation of mismatched indigenous, national and local structures that problems of governance are prone to arise.

In Higaunon areas, the barangay council might be made up of an assortment of citizens - including datus and baes of different types, ordinary Higaunons, and dumagat settlers. I know of many cases in which a cultural datu or bae also serves as a barangay officer, as well as a tribal council member for the ancestral domain. On the other hand, ancestral domains do not usually correspond to LGUS, and may even cut across more than one province or region, whilst a single barangay might encompass part of one domain but not the rest. Keeping track of these separate jurisdictions can be tricky for leaders and constituents alike, yet their considerable overlap in terms of people and places means that decisions made in one jurisdiction will inevitably have an impact on the others. In essence, interacting with the government has necessitated the creation of a new governing structure, parallel to Higaunon customary law, to enable community leaders to deal with these novel bureaucratic demands. The problem is that the corresponding mode of leadership that has emerged in this context operates on principles that are in direct conflict with traditional indigenous leadership.

To be sure, Philippine government bureaucracies can be gloriously inefficient and incompetent at any level. But the real problem lies in the fact that IP's have very little control over the multiple processes that affect them directly; the resulting jurisdictional confusion only amplifies their political vulnerabilities. Among the Higaunons, the problem appears subtle due to their extensive ancestral domain claims, their active participation in local government structures and other efforts to make themselves and their concerns visible to the state. But the truth is that, given the cultural, educational, economic and other disadvantages of Higaunons, it is still rare to find an indigenous leader - whether datu, siptin, or sirman - who is capable of dealing with the government bureaucracy, or the CADC/CADT requirements, or other matters 
entirely on his or her own. When circumstances require some degree of technical expertise or political networking, third party assistance, mentioned previously, typically comes into play. For example, as CADC or CADT 'holder,' the sirman typically turns to outsiders to facilitate their management plan, either through technical expertise (in agriculture, forestry, et cetera), fundraising, or even creating the management plan itself. According to the IPRA law, the NCIP is supposed to act as facilitator in such matters, but due to lack of funds and personnel they openly encourage IP communities to pair up with local or international NGOS who can provide the necessary technical assistance as well as the funds required to complete the many requirements of CADCs and CADTS. Furthermore, the assistance or patronage of third parties is often necessary for facilitating matters well beyond the management of ancestral lands, and NGOS, church-based social welfare groups and private individuals can easily carve out for themselves a role to play in bridging the gap between what is required of Higaunons and what they are able to provide on their own.

Sometimes 'facilitation' is simply a matter of advising or providing technical assistance, and sometimes it is a simple matter of aiding communication between an IP group and the government. Sometimes it involves merely providing background support to ensure that Higaunon are treated fairly and their rights are protected. For example, qualified Higaunons applying for college scholarships (to which they are entitled as IP's) are typically asked for a pile of paperwork (including certified birth certificates, et cetera) and official endorsements that may be costly or otherwise difficult to obtain, especially for the poor and disenfranchised. The process has been described to me by Higaunon students as not only daunting but also dizzying (both figuratively and literally), as they are usually sent around town to different government offices to chase down the required paperwork. The process is also deeply political, in that the endorsements are required from petty local officials in the local government unit and the NCIP, some of whom have been known to withhold their approval until they have been assured of political loyalty by the student's family, or in some cases, have extracted a bribe from already cash-poor students. ${ }^{19}$

19 One particular lower-level NCIP official is notorious for withholding scholarships - or absconding with them altogether - unless a student first 'shows her gratitude' by, for example, topping-up minutes for his prepaid mobile phone or 'giving change' for a large denomination peso bill that he never actually hands over in exchange. However, I hasten to point out that this is atypical and that all other NCIP officials I have met personally in fact do their work in a highly professional manner even with limited resources. The IP's grumble but are unwilling to file a formal complaint, fearing retaliation against their families due to the official's political connections. 
Students may therefore turn to third parties to either 'walk' their paperwork past such hurdles, or else give up on higher education altogether.

For Higaunons, the bureaucratic difficulties they routinely encounter are so overwhelming that it may well be impossible to complete even basic paperwork without the intervening gaze of outside observers. Whether this is merely a reflection of Higaunon insecurities or is due to active racial discrimination by dumagats, it highlights the very real cultural gulf between Higaunons on one hand and the dumagats (including the state that represents them) on the other. As a consequence, the interaction between 'indigenous' and 'state' political frameworks is so dependent on third party 'facilitators,' enabling outsiders to accumulate in the process a level of power and influence wholly disproportionate to their official position (if any) within either framework.

Amongst outsiders, the potential for real abuse is tremendous. In general, Higaunon communities are so vulnerable to exploitation and corruption that any individual with even modest financial means could easily amass great influence by providing scholarships for higher education or paying for emergency medical needs. ${ }^{20}$ Someone acting as a facilitator could become indispensable to community leaders as a government intermediary or 'fixer'. They could then turn around and exert undue influence over the tribal council, and over important matters like elections, or allowing the entry of logging or mining companies into an ancestral domain.

Within Higaunon society itself, the 'government datu' types like the siptin quickly acquire higher status within the community than they might otherwise possess within the bounds of customary law. In terms of pressing modern community needs like education, healthcare and the management of the ancestral lands, the siptin and sirman have now become essential political actors in a way that the 'cultural datu' may never be. As such, there is a serious power imbalance developing between the traditional political authority of the cultural datus and the rise of the government datus as a new locus of indigenous authority. Within the Higaunon context, the conceptualization of what constitutes legitimate political authority is now very much in flux.

Such competition for authority may well be unavoidable in the modern political context. However, the situation is complicated by the attempts of Higaunon datus to reconcile the authority of these new political actors within indigenous tradition and regulate their power by bringing them under the jurisdiction of the bungkatol ha bulawan or customary law. Inevitably they do

20 Paying for education and emergency medical care seem to be the two most pressing monetary needs amongst Higaunons in Misamis Oriental. 
this the only way they know how: by ritually confirming these new essential actors as datu or bae which, from the Higaunon point of view, formalizes a lifetime commitment to the community. The problem, of course, is that such individuals will not have undergone the years of training and testing normally considered necessary for a datu or bae to be confirmed. This means that they are unlikely to understand the bungkatol, much less consider themselves bound by it.

While all Higaunons recognize the need to accommodate the 'government datu' for the greater good, the principal danger lies in conferring the mantle of legitimacy on individuals who lack the requisite cultural knowledge. This in turn contributes to the growing political schism between the cultural and government datus within Higaunon society. Higaunons use black humour to critique this state of affairs, through the caricature of 'Datu Hag-as', whose ritual confirmation comes so quickly and prematurely that his 'sacred' name translates into English as 'Datu As-If.'21 Whilst this caricature definitely pokes fun at such datus - who are universally perceived as illegitimate or 'fake'- it is even more scathing a critique of the datus who sponsor such men for the sake of political expediency.

It becomes a different problem altogether when the datus allow the confirmation of non-Higaunons through the dumalungdong ritual. Heavy criticism is always levelled against those datus who do so in order to curry favour with potential dumagat allies. Local dumagat politicians, for example, are the usual beneficiaries of such honorary titles, as they are often useful in terms of political patronage. For the most part, the practice has proven relatively harmless, as such honorary datus or baes tend to disappear from Higaunon life afterwards. This is because they regard their titles primarily as touristic novelty or entertainment, rather than as a serious moral obligation to an IP community. However, this practice has also caused serious problems, as in the case of two 'fake' datus who attempted, in separate instances, to seize legal control of Higaunon territory by presenting themselves to state authorities as legitimate Higaunon datus.

The anomalous scenarios described above are a political reality today primarily because of the procedural gulf between Higaunon customary law and the state bureaucracy. In a sincere effort to render themselves more visible to the state, Higaunons have essentially 'invented' a parallel mode of governance

21 Hag-as in Cebuano Visayan is an expression that refers to something that happens suddenly, without precedent and for no apparent reason, implying that it is invalid, illegitimate, or otherwise highly suspect. 
that has proven practical and efficient, but also highly dissociative, with the government datu not only standing as the public alter of the 'real' datu, but ultimately pushing him aside. Meanwhile, the reliance on political patronage and third party facilitators leaves Higaunons and their loose, acephalous political system open to fraud, corruption, and abuse by outsiders like unscrupulous public servants and the 'fake' datus described above. While this has been a problem for decades, it has grown more acute with increased government decentralization and the continued administrative separation of IP's.

\section{Custom and Citizenship in the Philippine Uplands}

Higaunons do blame dumagats for many things, but the widespread loss of cultural knowledge and respect for tradition is blamed primarily on the shortsightedness of other Higaunons. This is in part due to the extensive adaptations to dumagat society and to the Philippine state that Higaunons have made over the past few decades. Despite their historical resistance to state and settler encroachment on their ancestral lands (Paredes 1997), Higaunons have made deliberate efforts since the 1990s to cultivate what they consider to be 'proper' citizenship in an effort to identify themselves as Filipino. For the most part this has involved assimilating where possible into dumagat culture, to make themselves appear less 'savage' and more 'citizenly' to dumagats. Yet the past two decades have witnessed a more substantial transformation in terms of Higaunon identification with the Filipino nation. Until the early 199os, within the context of intense, sometimes violent ancestral land struggles prior to the passage of the IPRA law, all my adult informants supported the idea of armed resistance against the government. Most expressed primarily separatist concerns: they wanted the dumagats to leave them alone, and the popular view was that anyone who married a dumagat was no longer a Higaunon. It was also considered acceptable to keep children out of the school system because it was deemed a dangerous distraction from the essential cultural formation of a Higaunon. This resistance to free government schooling was experienced by many datus born as late as the 196os, who form the main cohort of active community leaders at the moment.

Today, however, the same cohort appears primarily concerned with exercising their voting rights, registering as taxpayers, acquiring official birth certificates for their children and making great sacrifices to ensure that they finish school. They also take every opportunity to sign up for government programmes, dumagat associations, NGO programmes, church rosters and other ways through which they can signal their official membership in Philippine 
society. It is common, for example, for Higaunon males to possess an impressive array of papil (paperwork) identifying them as members of multiple churches as well as members of seemingly random dumagat associations. ${ }^{22}$ While they do discuss these activities, especially schooling, in the context of economic advancement for their families, they consistently refer to a desire to be recognized as being equal to other Filipino citizens. In their minds, bureaucratic visibility is the key to establishing their cultural legitimacy as citizens. Becoming Christian is also a popular choice, and Higaunons have joined any number of Christian sects active in their area, with some even forming their own Higaunon churches (Paredes 2006).

This has resulted in a novel dilemma for Higaunons. On a superficial level, cultivating proper citizenship has meant largely conforming to dumagat cultural markers such as education, wage labour, city attire and immersion in Filipino popular culture. With regard to political leadership, everyday realities necessitate the nurturing of individuals who are capable of interacting effectively with outsiders, and those who show intelligence and leadership ability are being encouraged generally to pursue formal schooling in the lowlands rather than training to be a datu. The ultimate goal, according to the datus I have interviewed, is to create a cadre of effective mediators and power brokers to protect the community's minority rights and other interests vis-à-vis the state and civil society. However, emphasizing assimilation and accommodation means de-emphasizing more Higaunon concerns, like the bungkatol ha bulawan, the oral traditions and cultural practices that might be perceived by dumagats as 'primitive'.

Meanwhile, Higaunons continue to pay lip service to the importance of cultural datus all the while pushing the next generation away from cultural datuship and down the path of dumagat assimilation, creating leaders who are culturally competent in the lowlands but detached from their own ancestral traditions. At the same time, the cultural datus are criticized for their general ineffectiveness in dealing with the pressing economic and political problems of Higaunon citizens in modern Philippine society. In day-to-day community affairs, the cultural datus are routinely pushed to the sidelines while siptins, sirmans and others who have networked with dumagats and outsiders for

22 However, most of these papil tend to be unofficial, and rather dodgy. I have even heard some older Higaunon men (who tend to be illiterate) claim that they didn't know what the organization actually was, and that they signed up only to have something with their name written on it. The possession of official government-issued identification papers the type that allows one to open a bank account or apply for a passport - remains relatively rare. 
political expedience have now become indispensable and, perhaps, a 'necessary evil.' As the politics of heritage becomes increasingly entangled with the politics of representation, the struggle between cultural and government $d a-$ tus complicates even further the goal of preserving Higaunon cultural heritage and ancestral lands. It seems inevitable that as they succeed in becoming more 'citizenly,' Higaunons and other IP's will lose touch with the ancestral traditions they have been fighting for.

The Philippine state's pursuit of a more inclusive democracy - in particular through 'participatory' approaches in development and governance - has, in a sense, opened up for Higaunons and other IP's a wider range of possibilities to assert their legal citizenship and expand their cultural citizenship. However, in valorising clientelistic dependence on more powerful and influential outsiders, their increased political participation also makes Higaunons vulnerable to more exploitation than was possible previously. Decentralization, in particular, has created new gaps that not only allow but virtually require the intervention of resourceful individuals who can mobilize government and other resources, as well as bridge the procedural gaps between indigenous and state systems. Unfortunately, the quotidian IP experience of democracy, as shown in the Higaunon case, is coloured significantly by the quality of the individual who steps into the breach. Whilst the process is breeding a new political elite amongst educated IP's who are more capable interlocutors vis-à-vis dumagat culture, it is also giving disproportionate power and authority to those who operate without the social and moral encumbrances of customary law. The most troubling aspects of the Higaunon case illustrate for us a defining irony of modern Philippine democracy: that the 'participatory' approaches advocated so often and so enthusiastically in fulfilment of the liberal, progressive ideals of inclusive citizenship, may in fact be transforming the IP's into 'new subalterns,' following Spivak (1999), whose exploitation is 'achieved precisely through the mobilization...of participation and empowerment in order to co-opt the local agency of communities at the margins within the neoliberal framework' (Dutta 2012:74). In other words, in their pursuit of empowerment - in this case through fuller citizenship and greater political participation as modelled by Filipino/dumagat culture rather than their own - Higaunons and other IP's may be instead achieving the opposite.

In the political context of Mindanao, citizenship has long been conceptualized, experienced and achieved differently by the minority IP's than the majority dumagats. As Rosaldo (2003:13) explains in his volume on cultural citizenship in the uplands of island Southeast Asia, cultural citizenship is about 'the kind and extent of participation by varied groups and individuals with different social projects'. For marginalized IP's in the peripheries of the 
nation-state, the politics of difference means that the state orders and 'constructs hinterland ethnic groups and...simultaneously excludes them from full citizenship' (Rosaldo 2003:14) in the process. If 'citizenship' is the precondition for having rights, at present the recognition that IP's 'belong' fully in Philippine society depends almost entirely on how they fit into preconceived notions of 'Filipino-ness'. As such, the more that Higaunons and other IP's struggle to 'belong' in this manner, the more they lose the cultural distinctiveness that makes the pursuit of fuller citizenship relevant in the first place. Their future in Philippine society will depend entirely on how they manage to challenge and transform the state's own cultural construct of citizenship.

\section{References}

Barter, S.J. (2015). 'Second-order' ethnic minorities in Asian secessionist conflicts: problems and prospects. Asian Ethnicity, 16(2), 123-135.

Brosius, J.P. (2003). The Forest and the Nation: Negotiating Citizenship in Sarawak, East Malaysia. In R. Rosaldo (Ed.), Cultural Citizenship in Island Southeast Asia: Nation and Belonging in the Hinterlands (pp. 76-126). Berkeley, CA: University of California Press.

Dutta, M.J. (2012). Culture-Centred Approach to Social Change Communication: Structure, Culture and Agency. In S. Melkote (Ed.), Development Communication in Directed Social Change: A Reappraisal of Theory and Practice (pp. 53-79). Singapore: Asian Media Information and Communication Centre.

Gaspar, K. (2013, October 10). The Politics of Statistics Involving the Lumad. Mindanews. Retrieved from http://www.mindanews.com/mindaviews/2013/10/10/a-sojourners -view-the-politics-of-statistics-involving-the-lumad/.

Hodgson, D.L. (2011). Being Maasai, Becoming Indigenous: Postcolonial Politics in a Neoliberal World. Bloomington, IN: Indiana University Press.

Li, T.M. (2001). Masyarakat Adat, Difference, and the Limits of Recognition in Indonesia's Forest Zone. Modern Asian Studies, 35, 645-676.

May, R.J. (2009). Federalism vs. Autonomy in the Philippines. In B. He, B. Galigan, \& T. Inoguchi (Eds.), Federalism in Asia (pp. 165-187). Cheltenham, UK: Edward Elgar.

McCargo, D. (2011). Informal Citizens: Graduated Citizenship in Southern Thailand. Ethnic and Racial Studies, 34 (5), 1-17.

McKenna, T. (1998). Muslim Rulers and Rebels: Everyday Politics and Armed Separatism in the Southern Philippines. Berkeley, CA: University of California Press.

Montiel, C., Rodil, R., \& de Guzman, J. (2012). The Moro Struggle and the Challenge to Peace Building in Mindanao, Southern Philippines. In D. Landis \& R. Albert (Eds.), 
Handbook of Ethnic Conflict: International Perspectives (pp. 71-9o). New York, NY: Springer.

Paredes, O. (1997). Higaunon Resistance and Ethnic Politics in Northern Mindanao. The Australian Journal of Anthropology, 8, 270-290.

Paredes, O. (2000). Discriminating Native Traditions Among the Mindanao Lumad. In C. Macdonald \& G. Pesigan (Eds.), Old Ties and New Solidarities: Studies on Philippine Communities (pp. 74-9o). Quezon City, Philippines: Ateneo de Manila University Press.

Paredes, O. (2006). True Believers: Higaunon and Manobo Evangelical Protestant Conversion in Historical and Anthropological Perspective. Philippine Studies, 54 (4), 521-559.

Paredes, O. (2013). A Mountain of Difference: The Lumad in Early Colonial Mindanao. Ithaca, NY: Cornell University SEAP Publications.

Paredes, O. (2015). Indigenous vs. Native: Negotiating the Place of Lumads in the Bangsamoro Homeland. Asian Ethnicity, 16(2), 166-185.

Rosaldo, R. (2003). The Borders of Belonging: Nation and Citizen in the Hinterlands. In R. Rosaldo (Ed.), Cultural Citizenship in Island Southeast Asia: Nation and Belonging in the Hinterlands (pp.1-15). Berkeley, CA: University of California Press.

Sahlins, M. (1963). Poor Man, Rich Man, Big Man, Chief: Political Types in Melanesia and Polynesia. Comparative Studies in Society and History, 5 (3), 285-303.

Spivak, G. (1999). A Critique of Postcolonial Reason: Toward a History of the Vanishing Present. Cambridge, MA: Harvard University Press. 